\title{
Perspective Cryptocurrency Projects Supported by China
}

\author{
Novrasta Asadova
}

\author{
Master's student, \\ International Finance Faculty, \\ Financial University, Moscow, Russia \\ novrasta96@gmail.com
}

Abstract

In this article are discussed the most perspective cryptocurrency and blockchain projects that China is investing in. After the regulations regarding cryptocurrencies that is put forth by China, the Chinese government decided to create several financial bodies to regulate and develop the cryptocurrency. Despite the strict regulation of cryptocurrencies, China has been significantly investing in blockchain projects. China has developed the Digital Currency Research Institute (DCRI) of the People's Bank of China - a research body under the aegis of PBOC that focuses on the research and development of digital currencies and blockchain-related technologies. China actively supports more than 40 platforms, mostly in such fields as Al, Deep Learning and Software. The Chinese government has shown a positive attitude towards blockchain technology. Blockchain and cryptocurrency come hand-in-hand (except a private chain where a token is unnecessary). In the nearest future, China plans to introduce a blockchain to the most different spheres. For this purpose, there will even double the volume of investment to 3 billion dollars, since the second quarter of 2018. "This technology can transform many spheres of our life. As soon as in the country pursue powerful technological policy, it is sure that even more companies will begin to work in the field of the blockchain" - the partner of the international consulting company PwC in Shanghai Chongg Chong Yin commented to journalists.

Keywords: cryptocurrency; regulations; finance; China; bitcoin; artificial intelligence; blockchain; FinTech; token JEL classification G19, G29

$\mathrm{D}$ ue to the technical and regulatory issues about the development of a state digital currency, China has developed the Digital Currency Research Institute (DCRI) of the People's Bank of China - a research body under the aegis of PBOC that focuses on the research and development of digital currencies and blockchain-related technologies. Also, it was included in the $13^{\text {th }}$ Five Year Plan. The Chinese central bank had established a research institute for the development of Digital Currency/Electronic Payment (DC/EP) with the approval of the State Council.

As of December 2018, DCRI had applied for a total of 63 digital currency patents, including 57 in 2017 and six in 2018.[1]

Despite being one of the most outspoken critics of Bitcoin, it is interesting to observe that the Chinese Government plans to embrace digital curren- cies based on blockchain technology, which is the basis of Bitcoin. Through the new research centre, the blockchain-based digital Yuan prototype will be tested before its official release to the public. The recent development is hardly the first significant step by the PBOC's Digital Currency Research Lab as it recently established a subsidiary called the Shenzhen FinTech Limited in another province called the Guangdong Province. Here, I present the five most undervalued coins that are supported by China.

\section{ELASTOS (ELA) - China's Internet 3.0}

The Elastos sets the task to process the concept of the use of the Internet and to unite its functionality with digital developments. The priority is put on the optimisation of the use of computing power, smart contracts and the decentralised 


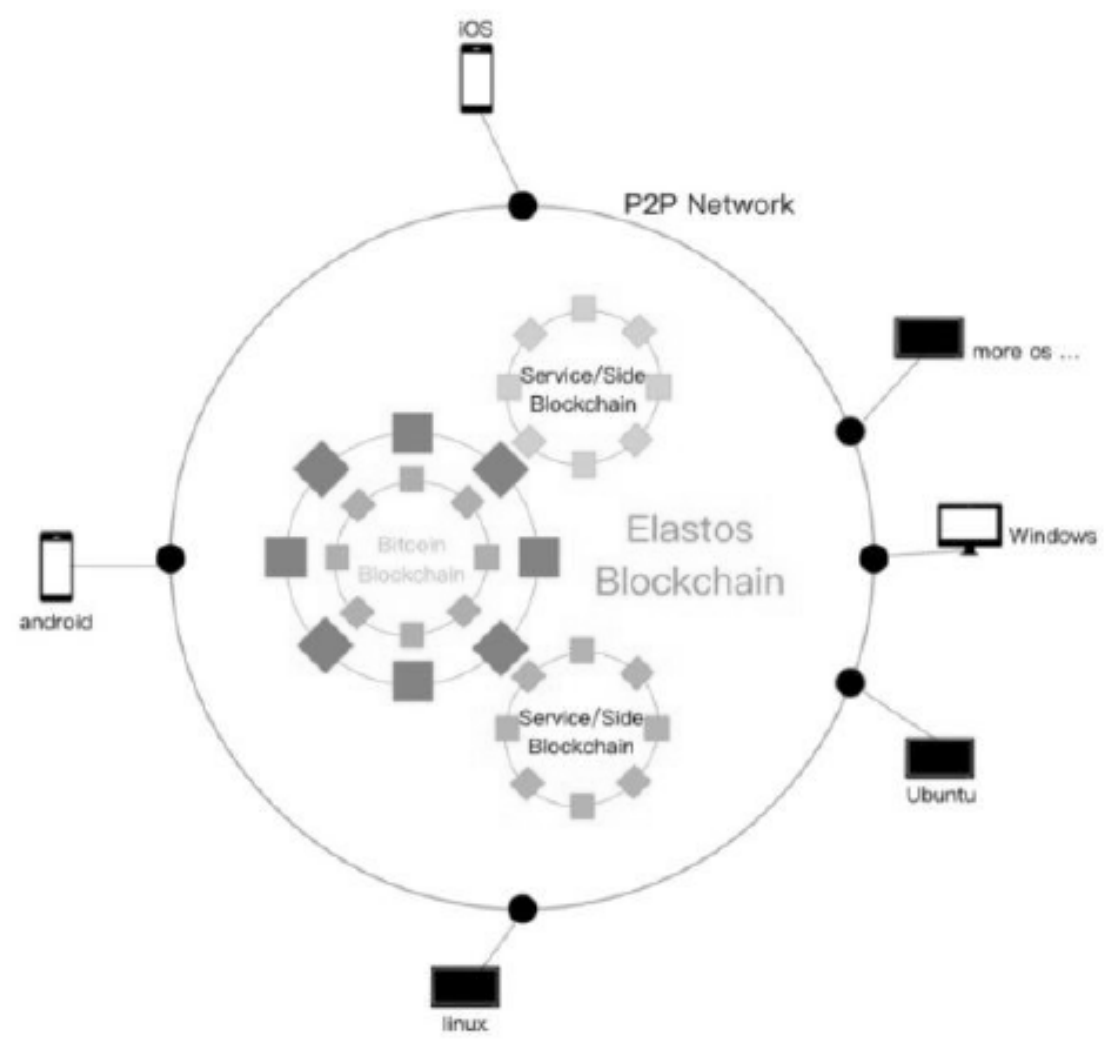

Fig. 1. Elastos Network system.

Source: coincost.net, 2019

applications and also the safety of all infrastructure for users.

First of all, Elastos is a new and safe Internet with no ads. Moreover, it is a platform to build DApps on. They're striving to solve the scalability issue by allowing other cryptocurrencies to run off of them on a sidechain.[2]

It is an "open source" project which got investments from more than 200 million yuan from the large companies (for example Foxconn Group). Elastos is devoted to the creation of absolutely new virtual digital intellectual, economic zone based on the traditional base of the Internet.

Structure of Blockchain Elastos is as follows:

The united production with Bitcoin. Safety and reliability provided using the computing power of Bitcoin. Such an idea of mining is less resourceintensive and provides more flexible solutions for different needs

The blockchain of Elastos provides applications with reliable communication between with each other and Elastos network (Fig. 1).

ELA Tokens are a part of Elastos system. So, this system allows creating own token or using ELA for transactions. Any token made on Elastos will be obliged to lock $2-5$ per cent of the total supply in ELA. It is very promising, considering such future DApps as Zapya with 400 million users, and Huawei, Alibaba, and, of course, future partners.[2] Users can use ELA tokens for registration in Elastots ID and use Elastos ID for the purchase of DApps, rent of cloud storage, and it is more than other digital services and products. As for $4^{\text {th }}$ March 2019, the price for 1 ELA is $\$ 3.25$ (Fig. 2). The market capitalisation is 47 million dollars.

Elastos is the biggest decentralised platform on the creation and management of decentralised applications (DApps). As this platform was created in China, so the command from Beijing bears responsibility for the development of a blockchain. The command from Shanghai is occupied with the development of OS (Elastos runtime), including support of the interface for communication with third-party applications.

Simply saying, it is similar to Windows. However, the difference between Elastos and Windows is that Elastos "open source" the project. Elastos is based on a blockchain that does it to the reliable and decen- 


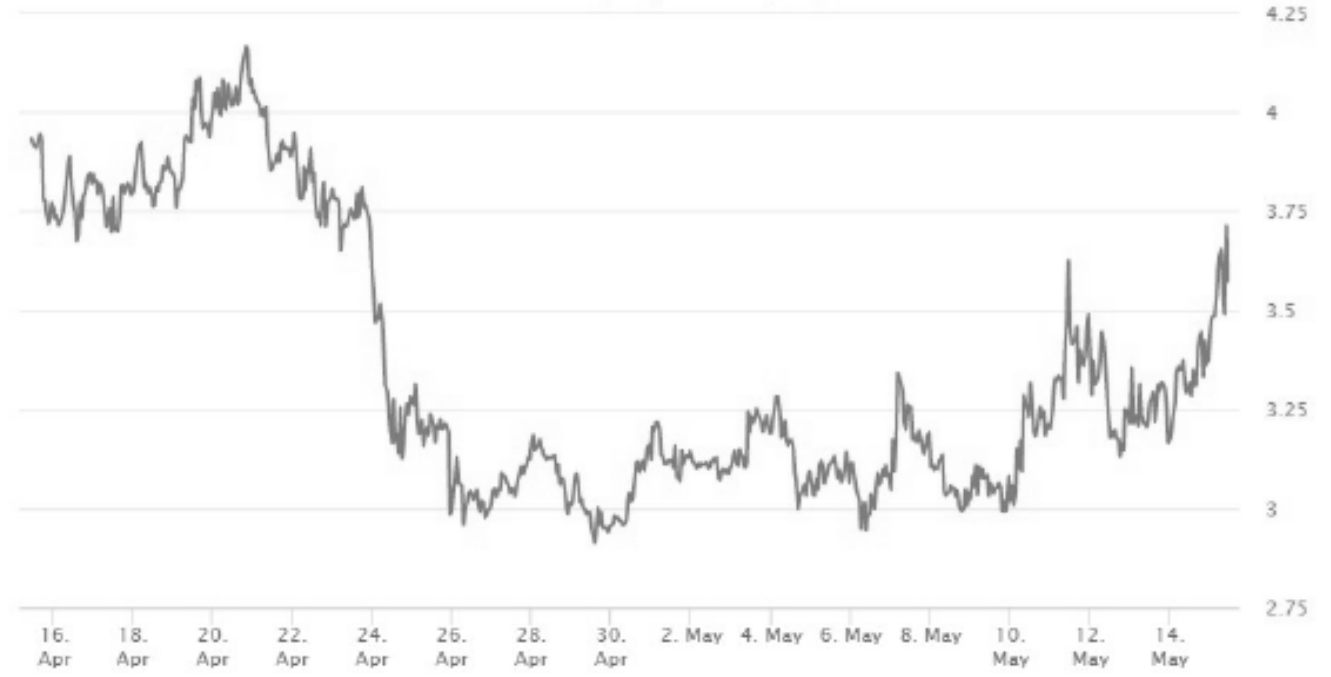

Fig. 2. Price of ELA to USD.

Source: coinmarketcap.com, 2019.

tralised OC, and Windows represents the traditional operating system - closed and centralised. To sum up, the central vision of Elastos is that it is intended to become the carrier which can carry out a set of the decentralised applications of big scale.

\section{MATRIX AI (MAN) - Codeless Chinese Cryptocurrency}

Matrix AI (MAN) is aiming to create a platform where you can create DApps and other cryptocurrencies through natural language programming.

It uses artificial intelligence and deep learning that learns over time how to auto-code for users. What this does is it brings the ability to create DApps and smart contracts to the masses. MATRIX AI Network was created to make blockchains quicker, safer, more flexible and more intellectual.[3]

MATRIX AI Network solves key problems which face the development of a blockchain and cryptocurrencies, there are:

The slow speed of transaction;

Programming of a barrier in smart contracts;

Lack of safety in smart contracts;

Shortcomings of management and updating of blockchains.

In 2018 MATRIX AI Network declared that it is the only blockchain project providing a strategic partnership with the Chinese initiative of One Belt One Road (OBOR) for one trillion dollars, which spans multiple continents and aims to enhance the trust and efficiency of trade between different economies it is a perfect match for blockchain technology.
"MATRIX brings good news to all the supporters of MATRIX and the Belt and Road initiative; we are proud to officially announce that have signed a strategic cooperation agreement with the state-owned Belt and Road Development Centre, to become the only blockchain partner of the centre." - Owen Tao, CEO.[4]

The MATRIX AI network assists in training and consulting in the areas connected with artificial intelligence and a blockchain and acts as the main applied platform for the centre. Besides, all contracts OBOR connected with a blockchain will pass through MATRIX AI network.

In May 2018 MATRIX AI Network announced the second partnership connected with OBOR, this time with the International company of digital assets (IDA) - the company on digitisation and tracking of assets which generally specialises in the OBOR enterprises. Today IDA owns assets for the sum about 3 billion US dollars in the form of natural resources. The partnership between IDA and MATRIX AI Network will allow digitisation further these natural resources using a blockchain of MATRIX AI Network. It will allow tracing more easily and effectively assets and also an opportunity quicker and more simply to transfer cost. IDA will also be one of the first applications of DApps started in MATRIX AI blockchain.

From 1,000,000,000 tokens of MAN, it was sold $150,000,000$ within the initial sale of tokens. The remained 850,000,000 tokens are reserved for the following purposes. It is an internal token using 


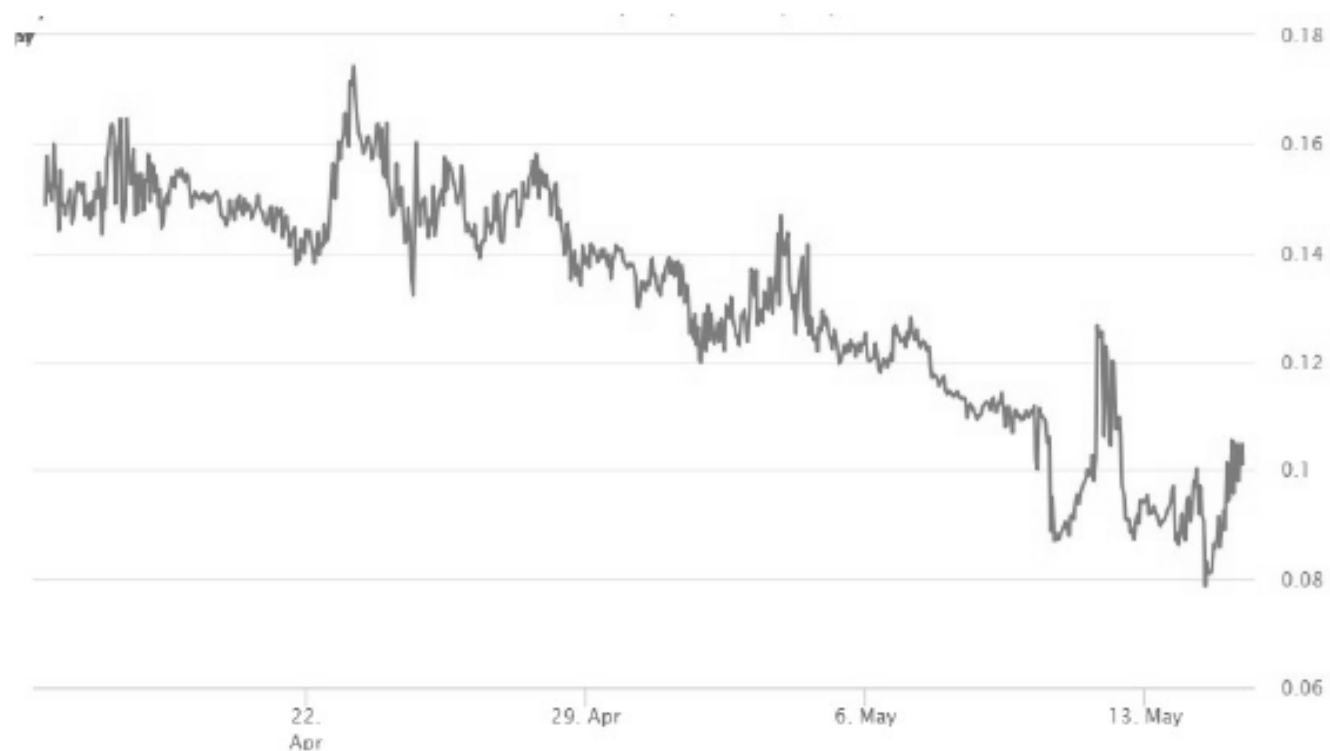

Fig. 3. Matrix Al Network Chart.

Source: coinmarketcap.com, 2019.

which miners will be rewarded and also paid the cost of the use of the platform for the creation of smart contracts. Also, it is possible to invest in tokens of MAN and for earnings due to the growth of their cost.

As at the initial stage the blockchain is not developed yet, Ethereum's blockchain is used, that is MAN standard ERC 20 tokens. In the future, after input of the blockchain tokens will be reissued and its holders will be able to exchange old coins for new in a proportion 1 to 1 . The issue is limited to 1 billion tokens of MAN. From this quantity within ICO are realised 150 million tokens, and 400 million are reserved for compensation of miners. A part of the rest will be sent to the reserve fund. Still, a quantity is distributed between the team of the project, advisers and partners.

According to Fig. 3, capitalisation of the project makes $\$ 79.143$ million that puts it on the 105 th place in the overall rating. The course makes $\$ 0.527619$ for one token of MAN today.

To sum up, it is hard to say whether this project will be successful or not, while there is not still full start. However, it shows yet good prospects for the future.

\section{HIGH PERFORMANCE BLOCKCHAIN (HPB) - Software and Hardware \\ Blockchain Solution Out East}

High Performance Blockchain (HPB) aims to be the fastest and most scalable platform for large institutions. Their goal is to run $1,000,000$ trans- actions per second (TPS). Transactions per second are essential because of supply and demand.

If you can only run, let's say five transactions per second, then when the network becomes popular and widely-used, if there is even a small amount, like 100 transactions per second, then the network fees become massive, as everyone is fighting for their transaction to go through.

It is the first blockchain to include the hardware component implementation. Thus, it is much faster than its competitors in this regard, positioning themselves to take on large Chinese companies like Alibaba and Tencent where there are millions of transactions a minute, High Performance Blockchain is setting itself up for a massive valuation.[5]

Implementation of High Performance Blockchain will allow to go beyond digital money and to transfer all document flow of the world to a blockchain. For implementation of this task, developers segmented the project hardware and program:

The hardware TOE card is connected to the network;

The updated architecture of a blockchain which will be connected as standard API is started;

The new algorithm is synchronised with the old network and increases its productivity.

As a result, the consumer has a high-performance system of a blockchain capable of working with any databases and of carrying out one million transactions per second. 


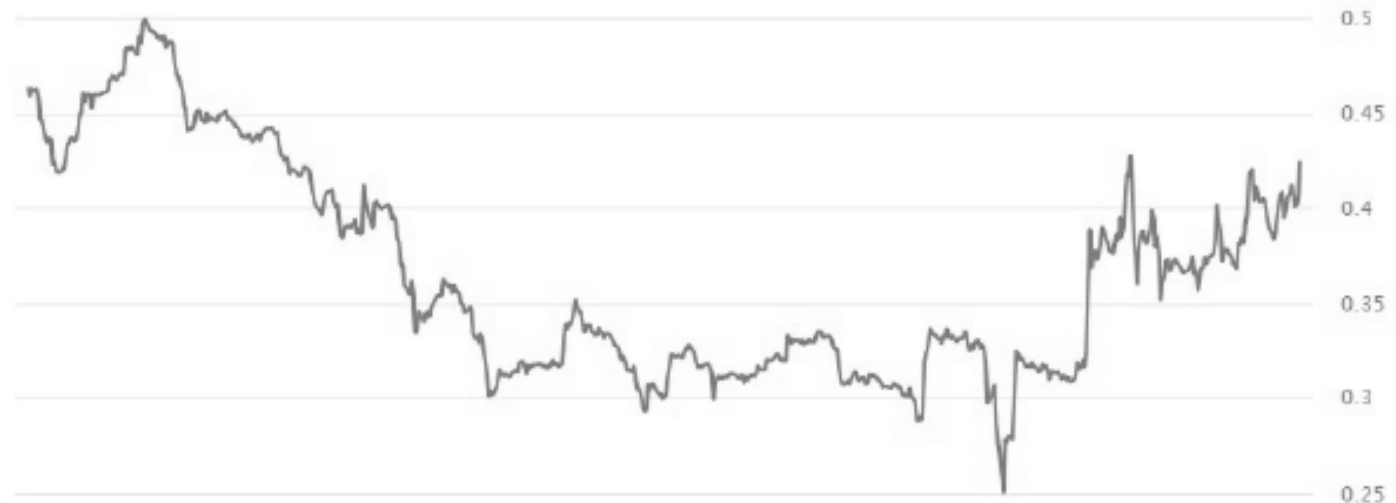

Fig. 4. High Performance Blockchain Chart.

Source: coinmarketcap.com, 2019.

On January 09, 2018 HPB token got on the Bibox crypto exchange. The base price for a coin was $\$ 2.96$. In total developers plan to produce 100 million HPB from which on February 15, 2018, in turn only 22 million. Unit price $-\$ 5.98$. Total capitalisation - 133 million US dollars. As of May 2019, price is 0.31 (Fig. 4).

To sum up, High Performance Blockchain is perspective technology, which will be interesting to all active blockchain projects. Special attention to it will be paid by the large corporations working with huge volumes of valuable information and needing its safe moving to different points of the world. The full version of the platform will appear not earlier than the end of 2019. By this moment, the High Performance Blockchain team plans to get sufficient financing and universal support. It will allow to bring at the beginning of 2020 a product to the world market and to start its further improvements.

\section{THEKEY (TKY) - Chinese Government- Backed Identification System}

THEKEY (TKY) wants to be the world's identity verification tool for citizen identity. And right now, it is on its way there. It is because it already partnered with the Chinese government to do precisely this. Put the prospective use case of this coin into perspective. It is already partnered with China - which is populated with over 1.3 billion people. If this takes off in China, then the sky is truly the limit for this coin.
China alone would put this coin's market capitalisation into the tens of billions. There are many, many years before this coin can get to full adoption, but by only taking a fraction of its potential market, this coin could genuinely explode.

Also, Developers closely cooperate with the NEO project, quite a perspective cryptocurrency.

The operability of the digital economy in many respects depends on whether users quickly will be able and with the minimum efforts to undergo verification, that is the identification of the personality. According to developers, any of the existing systems of identification does not provide the due level of reliability and speed of work.

The scheme looks like:

A particular parameter, for example, the fingerprint of the user or any other unique parameter allowing to select the person and to identify it is loaded into the database;

In need of verification, this parameter acted again and compared to what is stored in the base. As data fits, verification is considered successful.

Such an approach is accompanied by several problems, such as:

Identification is made only on 1 , or maximum two parameters that cannot provide the due level of reliability;

Data of the client are repeatedly duplicated when using different services. There is no uniform base in which information would be stored; 


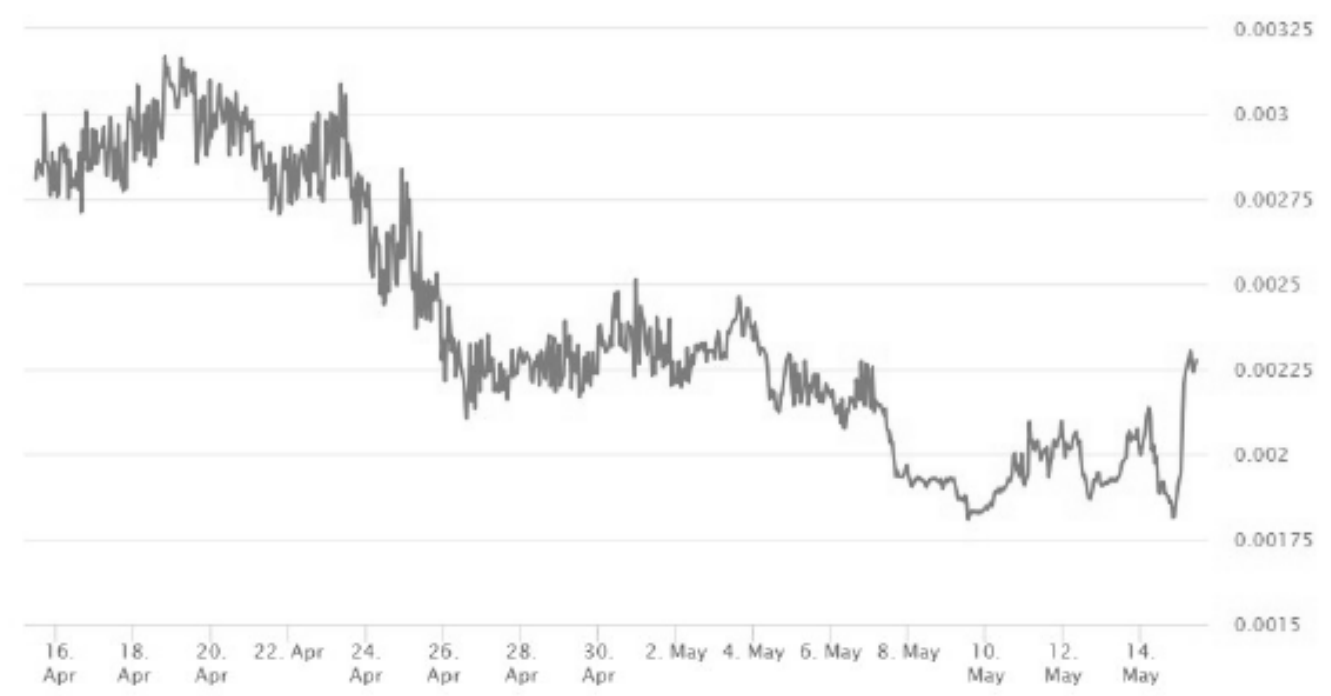

Fig. 5. THEKEY Chart.

Source: coinmarket.cap, 2019.

Even when using two-factor authentication (for example, the input of the password receiving SMS on the phone) there is a risk that malefactors will take control of them. That is the way of data storage has to be protected for 100 per cent of theft.

In THEKEY, all these problems are solved. Due to the use of a blockchain, it is impossible to steal or forge data. Here are solutions made by the platform:

There is realized multistage check at the identification of the personality. For example, besides a fingerprint also is assessed the activity of the person recently, the scheme of his movement;

Authors refused the centralised way of data storage. Instead of this DMI (dynamic multidimensional identification of the personality), it will be integrated into information centres of authorities;

The blockchain allows not worrying data will be stolen. It is impossible that they are stored not in one centre and on a set of the personal computer and if necessary, can be easily restored.

It is an internal currency of the project; it will be used for calculations between participants of the THEKEY project. It can be earned and at late stages of development of the project to use as a way of gaining access to the different products connected with identification. The THEKEY platform will use TKY tokens for the encouragement of validators and suppliers of data which will allow increasing the accuracy of work of a system.

TKY can be used as a natural object for investments. Entry into the exchanges already took place. Also, it can be used for cross-border payments; it can be divided. The general issue is equal to 10 billion TKY; the number of tokens will never exceed this size.

According to May 2019, capitalisation of the project makes $\$ 58,187$ million. Cost of one token of TKY is $\$ 0.00221$ (Fig. 5).

To sum up, identification of users is really promising market. Practically every person on the planet needs/will need services of this sort. So, the idea of the THEKEY project unambiguously working. The fact that the idea already began to be realised adds confidence in the project. In China, in several municipalities of operating time of THEKEY are used, and it gives quite a good effect.

\section{DEEPBRAIN CHAIN (DBC) - AI-Powered Chinese Blockchain}

DeepBrain Chain (DBC) aims to provide a lowcost, decentralised solution to the expensive AIcomputing problem that exists today. Artificial intelligence is one of the biggest buzzwords in tech today. This is because people understand that it is this, along with blockchain technology, are the future.[6] The problem with artificial intelligence, though, is that it is costly to compute. It is estimated that out of all AI start-ups funding, 30 per cent of it goes to their AI computing costs. DeepBrain Chain aims to lower the costs by an average of 70 per cent. It will drastically decrease the barrier of entry for AI start-ups, and help push the world faster and further into the future. 


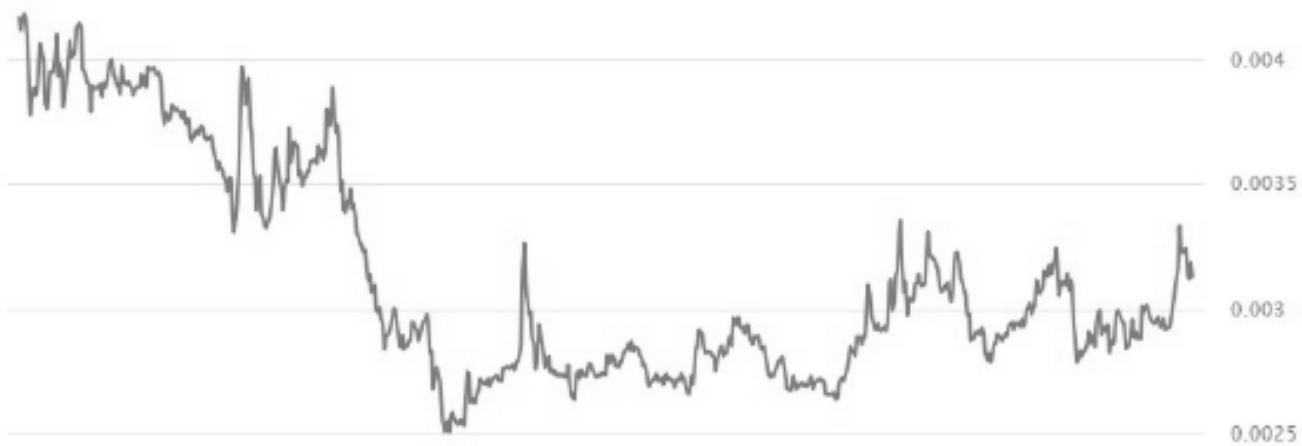

22. Apr

29 Apr

6. May

13. May

Fig. 6. DeepBrain Chain Chart.

Source: coinmarket.cap.

Also, there exists a library of semantics DeepBrain: library which supports applications for voice interaction (similarly to Amazon's Alexa). The library of semantics DeepBrain can be also used for the creation of third-party applications for which voice, graphic, text and other entrances are required.

Using technology Blockchain, DeepBrain Chain seeks to provide the inexpensive, private, flexible, safe and decentralised computing platform for artificial intelligence for products of artificial intelligence.

The group of founders is convinced that DeepBrain Chain already showed a precedent in the existing market, has the potential for scaling in the huge market and will be able gradually to grow around the primary activity on joint storage and the mechanism of the computing power of production.

Each DBC token corresponds to a calculated value of service. It means that the token is tied to the actual cost, and if DeepBrain Chain can advance this ambitious project, investors will be able to see quite essential dividends.

If DeepBrain Chain can prove as the pioneer in AI space on a basis a blockchain, it will have an essential basis in the potentially trillionth industry. Experts predict that the role of artificial intelligence will continue to grow with the advent of the AI new applications.

Nowadays, the AI industry costs about 20 billion dollars a year, and most of the expenses are spent on processing of calculations.[7] It where DeepBrain Chain fits as it uses a blockchain for cost reduction and increases in the speed of transactions.
DeepBrain Chain offers:

Low cost: DeepBrain Chain is directed to the depreciation of hardware input as the payment for GAS, which is required for each enterprise is, much less than an internal payment;

Optimisation: DeepBrain Chain is optimised on the graphics processor CUDA now and is going to be connected to the existing main system of deep learning, such as TensorFlow, Caffe, CNTK;

Highly competitive: DeepBrain Chain uses the unique technology of balancing of loading, each container of a node can interact with each other for sharing of pressure;

Confidentiality: in using the intellectual contract, the blockchain technology allows to divide the property rights into granting and the rights of use;

Flexible calculations: Frequency during peak hours can be in 10 times more in comparison with, not peak hours. DeepBrain Chain can be configured automatically by fast replication on several single nodes in rush hours.

AI on a blockchain is what else should be studied; only a few projects work now in this space. Therefore, DeepBrain Chain can get advantage before the first movement with a very smaller competition with which it is necessary to deal at the moment.

According to the graph, in May 2019, the cost of DBC token 0.02752 USD (Fig. 6). And market capitalization 11,793,168 USD.

To sum up, DeepBrain Chain is a promising project. The most important DeepBrain Chain element 
consists that it is unique and not just tries to make what was already made by others. The working product and the existing clients do it even more attractive. Being constructed on NEO, the Chinese competitor of Ethereum, DeepBrain Child, will probably draw a lot of attention in the next months.

These are examples of several projects that are seemed to be perspective in future. Of course, it is difficult to say which one would succeed. However,
China is investing in lots of other projects that are in different fields. So, all question in that, how competently developers will organise advances of the idea and whether they will be able to realise all planned steps in 2020. The future of the projects seems quite good. Towards the end of 2019 , it will become finally clear whether these projects will be able to make a revolutionary step, or it will be limited only to the market of China.

\section{References}

CBNEDITOR. 2018. Digital Currency Research Institute of the People’s Bank of China. Chinese Banking news. http://www.chinabankingnews.com/wiki/digital-currency-research-institute-peoples-bank-china/.

Dobrinka Blagojevic. 2018. Elastos (ELA) is the solution for spam infested internet, but there are reasons for concern as well. Crypto Journal; https://captainaltcoin.com/elastos-ela-is-the-solution-for-spam-infested-internet-butthere-are-reasons-for-concern-as-well/.

Russell Campbell. 2019. MATRIX AI Network - An Easier, Faster, Safer Blockchain 3.0. http://www.bitrebels.com/business/matrix-ai-network-easier-faster-safer-blockchain/

Official website matrix.io

Jeremy Lawlor. 2018. Chinese Cryptocurrencies That Could Be Worth Billions - 5 Low Market Cap Cryptos with High Potential for Growth. https://cryptoguidepro.com/best-undervalued-chinese-cryptocurrencies/.

Julia Bossmann. 2016. Top 9 ethical issues in artificial intelligence. https://www.weforum.org/agenda/2016/10/ top-10-ethical-issues-in-artificial-intelligence/.

Official website deepbrainchain.org.

Перспективные криптовалютные проекты, поддерживаемые Китаем

Новраста Асадова

магистрант,

Международный финансовый факультет,

Финансовый университет, Москва, Россия

Аннотация. В статье рассматриваются наиболее перспективные криптовалютные и блокчейн-проекты, в которые инвестирует Китай. После пересмотра правил, установленных Китаем в отношении криптовалют, китайское правительство решило создать несколько финансовых органов для регулирования и развития криптовалюты. Однако, наряду со строгим регулированием криптовалют, Китай инвестирует значительные средства в блокчейн-проекты, в развитие Исследовательского института цифровой валюты Народного банка Китая, деятельность которого сосредоточена на исследованиях и разработках цифровых валют и технологий, связанных с блокчейном. Китай активно поддерживает более 40 платформ, в том числе в сфере создания искусственного интеллекта, глубинного обучения и программного обеспечения. В ближайшее время Китай планирует внедрить блокчейн в самые разные сферы экономики, увеличив объем инвестиций в его развитие до 3 млрд долл. «Эта технология может трансформировать многие сферы нашей жизни. Если в стране проводить мощную технологическую политику, я уверен, что еще больше компаний начнут работать в области блокчейна» - сказал журналистам партнер международной консалтинговой компании РwC в Шанхае Чунг Чонг Инь.

Ключевые слова: криптовалюта; регулирование; финансы; Китай; биткоин; искусственный интеллект; блокчейн; финтех; токен 